\title{
Melting Temperature of Thermally Reversible Gel. VI. Effect of Branching on the Sol-Gel Transition of Polyethylene Gels
}

\author{
Akira TAKAHASHI, Masato SAKAI, and Tadaya KATO \\ The Chemistry Department of Industry and Resources, Faculty of Engineering, \\ Mie University, Tsu, Mie 514, Japan.
}

(Received January 23, 1980)

\begin{abstract}
The gel-melting temperatures of branched polyethylene-cyclohexane-carbon disulfide gels were measured. Branched polyethylenes having a different number of long-branching points were used. The reciprocal of the gel-melting temperature is a linear function of the logarithm of the polymer concentration. A theory which predicts the gel-melting temperature of branched crystalline copolymers is given. Analysis of the experimental data suggests that the size of the crystalline junction decreases with an increase in the number of long-branching points.

KEY WORDS Sol-Gel Transition / Branched Polyethylene / Gel / GelMelting Temperature / Polyethylene /
\end{abstract}

It is well known that polyethylene is precipitated as crystalline lamella from its dilute solution upon cooling. However, another type of crystallization is known, in which the separation of the crystalline phase from solution does not occur, but the whole solution converts to a gel, indicating crystallinity. ${ }^{1-11}$

It is well recognized that the copolymeric character of a crystalline polymer is conductive to gelation. ${ }^{1,11}$ Polyethylene, which has both short and long branches, is a crystalline copolymer and, indeed, Matsuda, Araki, and Kuroiwa ${ }^{12}$ discovered that on cooling a branched polyethylenecyclohexane-carbon disulfide solution, the whole system is converted to a gel instead of separating into crystalline phases. Moreover, they found that the gel is crystalline, since $\mathrm{X}$-ray diffraction pattern indicated the crystalline order of the polyethylene crystal. If gelation takes place, cross-linking loci should be present in the system. It is considered that the crystallites perform the role of cross-linking loci. They reported gel-melting temperatures as a function of polymer concentration as well as molecular weight; however, no detailed thermodynamic analysis of a gel-sol transition was attempted. In the previous papers of this series, we presented a thermodynamic analysis of the gel-melting temperature of various gels formed by synthetic polymers. In this paper, we extend the previous theoretical treatment of the gel-melting temperature to include branched polymers and the new theory is compared with experimental gel-melting temperature data measured for well characterized polyethylenes having long branches.

\section{EXPERIMENTAL}

\section{Materials}

Three polyethylene samples each having a different number of long branches have been used. Characterization of these samples was carried out by Nakano and Goto. ${ }^{13}$ And their characteristics are given in Table I. Benzene, cyclohexane, and carbon disulfide were distilled before use. Benzophenone (Nakarai Chem. Ltd.) was used as received.

\section{Gel-Melting Temperature}

The gel-melting temperature apparatus shown in Figure 1 was used. The apparatus has an arm in which a steel ball (less than $100 \mathrm{mg} w \mathrm{w}$ ) is placed. A weighted amount of polyethylene was placed in the bottom of the apparatus and a weighted amount of $1: 1$ volume ratio cyclohexane and carbon disulfide mixed solvent was added. The apparatus was then sealed. It was placed in a thermostat which maintained at $80^{\circ} \mathrm{C}$ and the polymer sample was dis- 
Table I. Characteristics of branched polyethylene

\begin{tabular}{cccccc}
\hline Samples & $M_{n} \times 10^{-4}$ & $M_{w} \times 10^{-4}$ & $\mathrm{CH}_{3} / 1000 \mathrm{C}^{\mathrm{a}}$ & $\lambda \times 10^{5 \mathrm{~b}}$ & $\lambda M_{w}$ \\
\hline A & 2.30 & 12.6 & 27 & 5.7 & 7.18 \\
$\mathrm{~B}$ & 2.56 & 10.1 & 22 & 0 & 0 \\
$\mathrm{C}$ & 2.24 & 15.1 & 23 & 2.7 & 4.07 \\
\hline
\end{tabular}

a Fraction of short branches.

b $\lambda M_{w}=m$ is the number of branch points of long branches per polymer.

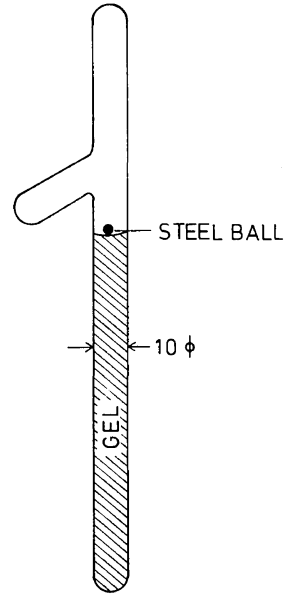

Figure 1. The gel-melting temperature apparatus.

solved. After dissolution, the apparatus was placed in a thermostat kept at $20^{\circ} \mathrm{C}$, and gelation was carried out for $16 \mathrm{~h}$. After gelation, the steel ball was placed on the top of gel by magnetic manipulation. The gel was then heated at the rate of $0.4^{\circ} \mathrm{C}$ $\mathrm{min}^{-1}$ and the height of the steel ball was recorded with temperature. When the gel melts, i.e., converts to a sol, the steel ball starts to move downward. Typical examples of measurements are shown in Figure 2. The intersection of two straight lines was taken as the gel-melting temperature. The effect of the weight of the steel ball on gel-melting temperatures was examined. It was found that the gel-melting temperature did not depend very much on the weight of the ball as long as it was less than $100 \mathrm{mg}$.

\section{Swelling Experiment}

A low-density polyethylene film $(0.5 \mathrm{~mm}$ thickness) $\left[M_{n}=2.37 \times 10^{4}\right]$ was immersed in a $5 \mathrm{wt} / \mathrm{wt} \%$ benzene solution of benzophenone for $24 \mathrm{~h}$. Then the film was irradiated by UV light for $200 \mathrm{~min}$ and

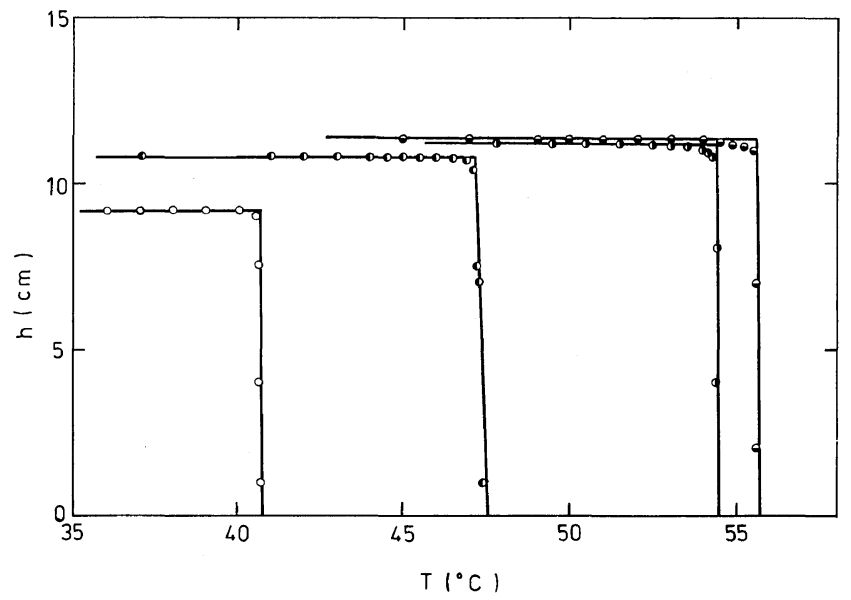

Figure 2. Examples of the measurements of gel-sol transition temperatures. Sample A. Volume fraction of polymers: $\bigcirc, 0.065 ; 0,0.079 ; \bigcirc, 0.097 ; \ominus, 0.113$. 
photocross-linked. The film was extracted by boiling benzene in a Soxhlet apparatus.

Swelling experiment was carried out as follows: after the weight of the film was determined, the crosslinked film was swelled in $p$-xylene for $24 \mathrm{~h}$ at $72.7^{\circ} \mathrm{C}$ and the weight of swelled film was determined.

From the swelling ratio, the volume fraction of polymer $v_{2}$ was determined. The molecular weight between the cross-linked points $M_{\mathrm{c}}$ was calculated by ${ }^{14}$

$$
\begin{aligned}
M_{\mathrm{c}}= & M_{n} \mathrm{~d} v_{0}\left(v_{2}{ }^{1 / 3}-2 v_{2} / v\right) /\left\{2 \mathrm{~d} v_{0}\left(v_{2}{ }^{1 / 3}-2 v_{2} / v\right)\right. \\
& \left.-M_{n}\left[\ln \left(1-v_{2}\right)+v_{2}+\gamma_{1} v_{2}{ }^{2}\right]\right\}
\end{aligned}
$$

where $d$ is the density of the film, $v_{0}$ is the molar volume of solvent, $v$ is the functionality of a crosslinked point, $M_{n}$ is the number-average molecular weight of the sample before cross-linking and $\chi_{1}$ is the interaction parameter. Making use of $v=3$ and $\chi_{1}=0.511$ for polyethylene- $p$-xylene pair, ${ }^{15} M_{\mathrm{c}}$ was determined as 6138 .

Having established $M_{\mathrm{c}}$, the same film was swelled in a $1: 1$ volume mixture of cyclohexane and carbon disulfide at $25^{\circ} \mathrm{C}$, and the swelling ratio was determined. The $\chi_{1}$ parameter for polyethylenecyclohexane-carbon disulfide mixed solvent was calculated by eq 1 .

\section{RESULTS AND DISCUSSION}

When polethylene-cyclohexane-carbon disulfide solutions were converted to gels, they exhibited turbidity. The gel converted to a sol at about 40 to $70^{\circ} \mathrm{C}$ depending on the number of long branches. The increase in the number of long branches resulted in a lower gel-melting temperature $\left(T_{\mathrm{m}} \mathrm{g}\right)$. Gelmelting temperatures increased with increase in polymer concentration. In Figure $3,1 / T_{\mathrm{m}}{ }^{\mathrm{g}}$ is plotted against the logarithm of polymer concentration and straight lines are obtained, indicating that the relationship due to Eldridge and Ferry ${ }^{16}$ holds; that is,

$$
\ln v_{2}=\text { const }+\Delta H_{\mathrm{m}} / R T_{\mathrm{m}} \mathrm{g}
$$

Here, $\Delta H_{\mathrm{m}}$ is the heat absorbed on formation of a mole of the junction points. From Figure 3, it is apparent that $\Delta H_{\mathrm{m}}$ depends on the number of long branches in each polyethylene sample. However, the Eldridge and Ferry relationship does not indicate the molecular mechanism or model of gelation. According to Matsuda, Araki, and Kuroiwa, ${ }^{12}$ the

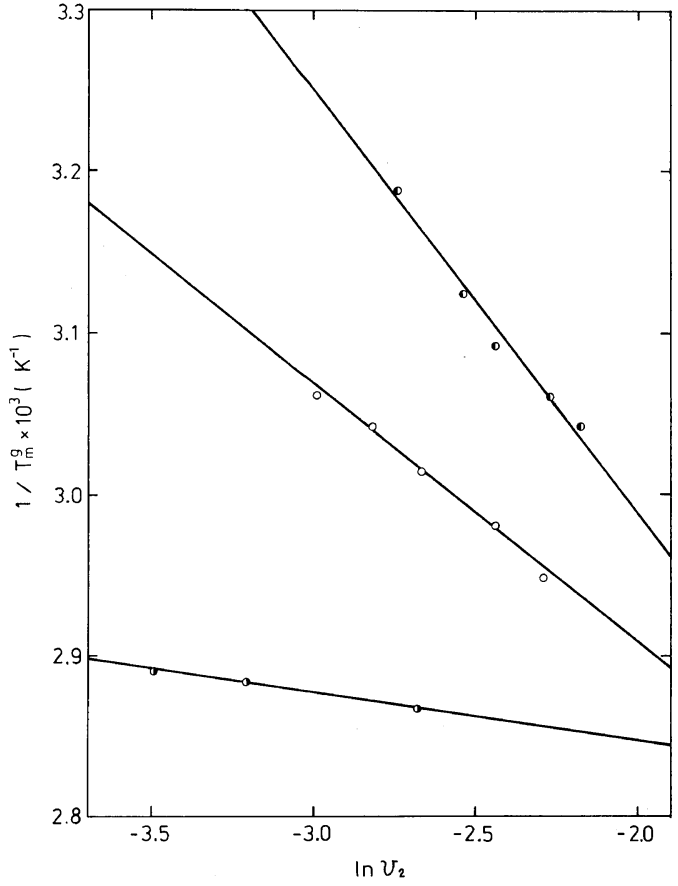

Figure 3. The reciprocals of the gel-melting temperature $v s . \ln v_{2}$ plots for samples: $\mathbf{D}, \mathrm{A} ; \boldsymbol{O}, \mathrm{B} ; \bigcirc, \mathrm{C}$.

polyethylene-cyclohexane-carbon disulfide gel exhibits wide angle X-ray diffraction. Therefore, crystallites consisting of ethylene unit behave as crosslinking junction points.

Branching points in a branched polyethyene are trifunctional and these points exist along a trunk chain. However, to simplify the theoretical treatment of a gel-melting temperature of a branched polymer, an unorthodox way is to assume that the branched polyethylene is an $f$-star branched polymer. Then, if a crystallite is $\zeta$ ethylene-unit long and consists of $\rho$ crystalline sequences, the theory in the Appendix assumes that only one equilibrium is involved, i.e.,

$$
\rho \text { (crystalline sequences) } \rightleftarrows 1 \text { crystallite }
$$

Though the gel-melting point is not the thermodynamic singularity, according to this theory, the gelmelting temperature is given as follows.

$$
\begin{aligned}
& 1 / T_{\mathrm{m}}{ }^{\mathrm{g}}=\zeta /\left(\zeta \Delta h_{\mathrm{u}}+\zeta B^{\prime} V_{\mathrm{A}}-2 \sigma_{\mathrm{ec}}\right) \\
& \quad \times\left(\Delta h_{\mathrm{u}} / T_{\mathrm{m}}{ }^{\circ}+R V_{\mathrm{A}} / V_{1}-R \ln \psi_{\mathrm{A}}\right) \\
& - \\
& \quad R / \rho\left(\zeta \Delta h_{\mathrm{u}}+\zeta B^{\prime} V_{\mathrm{A}}-2 \sigma_{\mathrm{ec}}\right) \\
& \quad \times\left\{\ln \left\langle M_{w}\right\rangle+(\rho-1) \ln v_{2}+\ln \rho[\rho(f-1)-1]\right\}
\end{aligned}
$$




\section{A. Takahashi, M. Sakai, and T. Kato}

In the equation, $\Delta h_{\mathrm{u}}$ is the heat of fusion of an ethylene unit, $B^{\prime}$ is the cohesive energy density defined by $\chi_{1}=B^{\prime} V_{1} / R T, \sigma_{\mathrm{ec}}$ is the end interfacial free energy per crystalline sequence, $T_{\mathrm{m}}{ }^{\circ}$ is the melting temperature of polyethylene, $X_{\mathrm{A}}$ is the mole fraction of crystalline units, $M_{w}$ is the weight-average molecular weight, $v_{2}$ is the volume fraction of the polymer in the gel, and $V_{\mathrm{A}}$ and $V_{1}$ are the molar volumes of a crystalline unit and solvent, respectively.

For a linear polymer, $f$ is equal to 2 and for the branched polyethylene with the number $m\left(=\lambda M_{w}\right)$ of branching points in the long branches, $f$ is $(m+2)$. Equation 4 differs from our previous equation for the gel-melting temperature, ${ }^{1,17}$ in which the functionality $\rho$ of crystalline junction was neglected.

If quantities other than $\rho$ and $\zeta$ are known, then eq 4 enable us to estimate both $\rho$ and $\zeta$ from experimental gel-melting temperatures. The procedure is as follows. Assuming a value for $\rho$, then $1 / T_{\mathrm{m}}{ }^{\mathrm{g}}$ is plotted against

$$
\left\{\ln \left\langle M_{w}\right\rangle+(\rho-1) \ln v_{2}+\ln \rho[\rho(f-1)-1]\right\}
$$

and from the intercept and the slope thus obtained, $\zeta$ and $\rho$ are evaluated. This procedure is repeated until the assumed $\rho$ and the evaluated $\rho$ coincide. From the swelling experiment in the cyclohexane-carbon disulfide mixed solvent, $\%_{1}$ was estimated to be 0.636 resulting $B^{\prime}=4.45 \mathrm{cal} \mathrm{ml}^{-1}$. For $\sigma_{\mathrm{ec}}$, the value 2840 cal $\mathrm{mol}^{-1}$ of sequence estimated for ethylene-vinyl acetate copolymer gel $^{2}$ was employed. $X_{\mathrm{A}}$ is identical with $\left[1-0.001\left(\mathrm{CH}_{3} / 1000 \mathrm{C}\right)\right]$ and $f$ is taken to be equal to $\lambda\left\langle M_{w}\right\rangle+2$. Making use of $\Delta h_{\mathrm{u}}=1920 \mathrm{cal}$ $\mathrm{mol}^{-1}, T_{\mathrm{m}}{ }^{\circ}=418.6 \mathrm{~K} V_{\mathrm{A}}=28 \mathrm{ml} \mathrm{mol}^{-1}$ and $V_{1}=$ $84.67 \mathrm{ml} \mathrm{mol}^{-1}$, the above procedure was applied for estimating both $\rho$ and $\zeta$. The results are summarized in Table II and shown in Figures 4 and 5.

Table II. The estimated $\rho$ and $\xi$

\begin{tabular}{crc}
\hline Samples & $\rho$ & $\xi$ \\
\hline A & 2 & 4.7 \\
B & 14 & 33 \\
C & 2 & 5.8 \\
\hline
\end{tabular}

The melting temeperature of normal paraffin having a carbon number of 66 is $376.8 \mathrm{~K}$ and the gelmelting temperature of sample B $(\zeta=33$ ethylene units) is $346 \mathrm{~K}$. If the melting point depression of crystallites caused by the solvent is taken into consideration, then the values $\rho$ and $\zeta$ for sample B are reasonable. However, for samples $\mathrm{A}$ and $\mathrm{C}$, the estimated values of $\zeta$ are too small, since the melting temperature of normal paraffin of carbon number $11^{18}$ is $245 \mathrm{~K}$, which is lower than the gel-melting

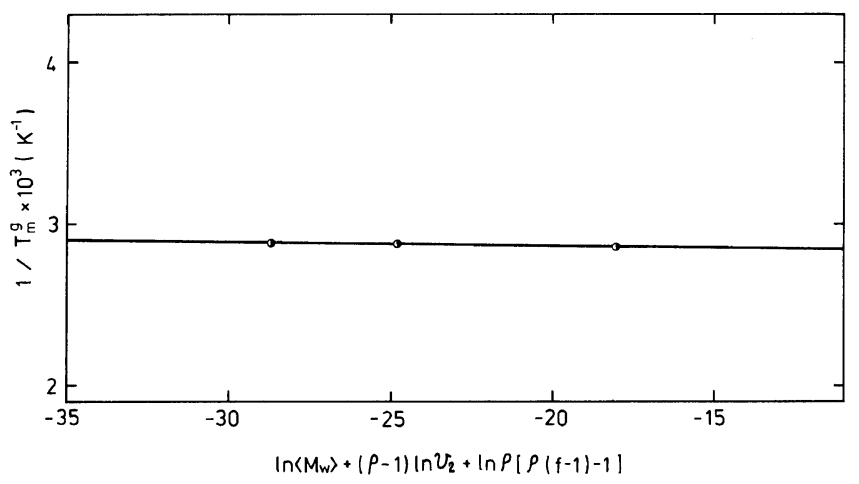

Figure 4. The reciprocals of the gel-melting temperarure $v s$.

$$
\left\{\ln \left\langle M_{w}\right\rangle+(\rho-1) \ln v_{2}+\ln \rho[\rho(f-1)-1]\right\} . \quad \text { Sample B. }
$$




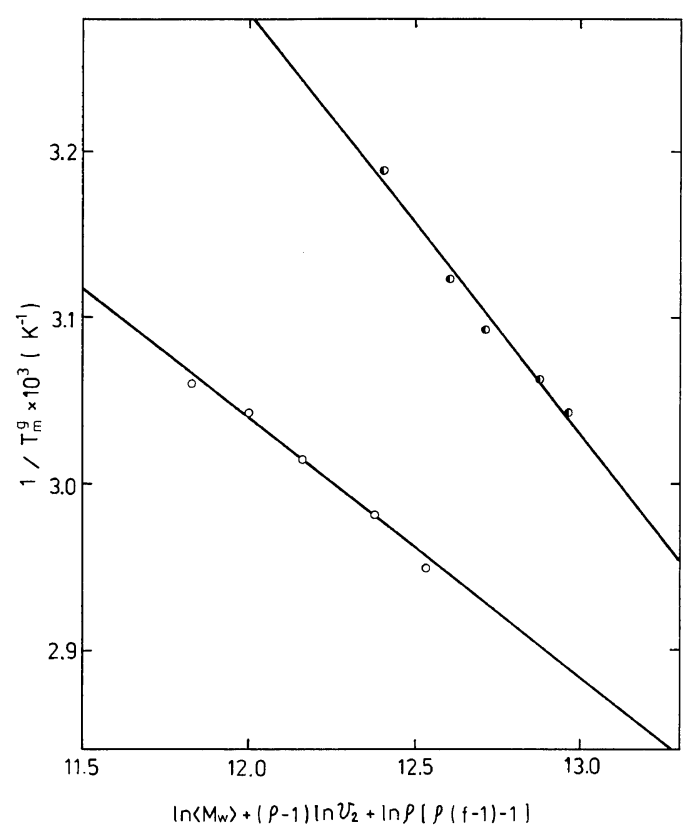

Figure 5. The reciprocals of the gel-melting temperature $v s$.

$$
\left\{\ln \left\langle M_{w}\right\rangle+(\rho-1) \ln v_{2}+\ln \rho[\rho(f-1)-1]\right\}
$$

for samples: $\mathbf{D}, \mathrm{A} ; \mathrm{O}, \mathrm{C}$.

points, i.e., $T_{\mathrm{m}}{ }^{\mathrm{g}} \simeq 320 \mathrm{~K}$ for sample $\mathrm{A}$ and $T_{\mathrm{m}}{ }^{\mathrm{g}} \simeq 330 \mathrm{~K}$ for sample $\mathrm{C}$. The estimated $\zeta$ depends crucially on the assumed $\sigma_{\mathrm{ec}}$, and we selected $\sigma_{\mathrm{ec}}=2840 \mathrm{cal} /(\mathrm{mol}$ of sequence $)$. And this value is also identical to the interfacial free energy of polyethylene single crystals. It was seen that a much higher $\sigma_{\mathrm{ec}}$ value results in a higher $\zeta$. Because of the uncertainty in the value of $\sigma_{\mathrm{ec}}$ for fringed micellar crystallites, we, therefore, do not give much credence to an absolute value of $\zeta$; however, the order of crystallite size is correct since the gel-melting points are also in this order. The turbidity of gels is also in this order, since crystallite size and number determine the turbidity. The value of $\rho$ does not depend so much on an assumed value of $\sigma_{\mathrm{ec}}$. The value, $\rho=2$ is the minimum number of crystalline sequences to form crystalline nuclei, which appear at the gelmelting point.

Since branched polyethylene is not a star branched polymer, the assumption of crystallization of star branched polymers given in the Appendix is open to criticism. If trunk chains are incorporated into the crystallite, then the value of $f$ is varied. However, it was found that the variation in the value of $f \operatorname{did}$ not affect very much the values of $\rho$ and $\zeta$ estimated.
Thus, we may expect that the assumption of a star polymer is not entirely wrong or that branched polyethylene is resembles a star polymer.

In conclusion, the crystallite size decreases with an increase in the number of long branches resulting from a lower gel melting point.

Acknowledgment. Special thanks are due to Messrs. S. Nakano and Y. Goto, Mitsubishi Petrochemical Co. for supplying the polyethylene samples.

\section{APPENDIX}

Consider an $f$ star branched crystalline copolymer in a solution, and that these $\rho$ copolymers gather to form a crystallite consisting of $\rho$ crystalline sequences and $\zeta$ units long as in Figure A-1. The branches of the crystallized copolymers further crystallize to form other crystallites having $\rho$ sequences. These crystallites act as cross-linking junctions, and so the critical branching coefficient, $\alpha_{c}$, is given by ${ }^{19}$

$$
\alpha_{\mathrm{c}}=1 /[\rho(f-1)-1]
$$

Denoting the critical number of crystallites as $N$ $\left(\mathrm{g} \mathrm{ml}^{-1}\right), \alpha_{\mathrm{c}}$ may be alternatively written as

$$
\alpha_{\mathrm{c}}=N /\left(v_{2} / x V_{1} \rho\right)
$$

where $v_{2}$ is the volume fraction of the polymer, $x$ is the number of segments in a polymer, $V_{1}$ is the molar volume of the solvent. The following equilibrium is considered to be

$$
\begin{gathered}
\rho \text { potential crystalline sequences } \\
1 \rho \text {-fold crystalline junction }
\end{gathered}
$$

The equilibrium constant may thus be written as

$$
K=N \bar{v} / v_{2}{ }^{\rho}=\exp (-\Delta F / R T)
$$

where $\bar{v}$ is the partial specific volume of a crystallite and $\Delta F$ is the free-energy change accompanying the transformation of $\rho \zeta$ units from solution to a crystallite $^{1}$ :

$$
\begin{aligned}
\Delta F= & \rho\left[2 \sigma_{\mathrm{ec}}-\zeta \Delta f_{\mathrm{u}}+\zeta R T\left(V_{\mathrm{A}} / v_{1}\right)\left(1-\chi_{1}\right)\right. \\
& \left.-\zeta R T \ln X_{\mathrm{A}}\right]+2 \zeta \sigma_{\mathrm{u}}(\pi \rho)^{1 / 2} \\
& \simeq \rho\left[2 \sigma_{\mathrm{ec}}-\zeta \Delta f_{\mathrm{u}}+\zeta R T\left(V_{\mathrm{A}} / v_{1}\right)\left(1-\chi_{1}\right)\right. \\
& \left.-\zeta R T \ln X_{\mathrm{A}}\right]
\end{aligned}
$$




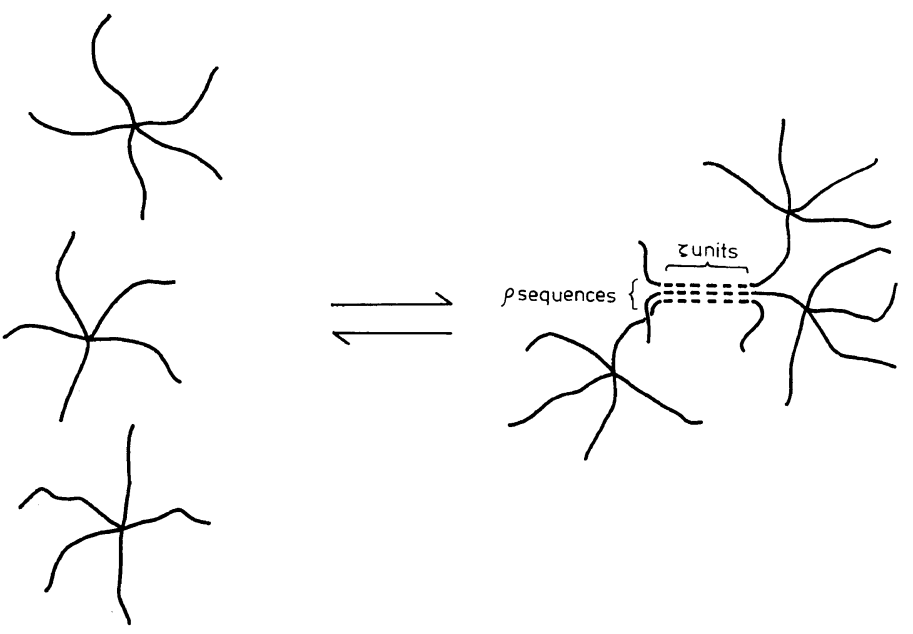

Figure A-1. $\rho$ of $f$-star branched crystalline copolymers gather to form a crystallite with $\rho$ crystalline sequences and $\xi$ units long.

In the above equation, $\sigma_{\mathrm{ec}}$ and $\sigma_{\mathrm{u}}$ are the end and the lateral interfacial free energies, $\Delta f_{\mathrm{u}}$ is the free energy of fusion per crystalline unit, $\chi_{1}$ is the interaction parameter, $X_{\mathrm{A}}$ is the mole fraction of crystalline units, and $V_{\mathrm{A}}$ and $V_{1}$ are the molar volumes of a crystalline unit and solvent, respectively. In eq A-6, the contribution of the lateral interfacial free-energy term is neglected since in general, $\sigma_{\mathrm{u}}$ is very small. From eq A-1, A-2, A-4, and A-6, we obtain,

$$
\begin{aligned}
v_{2} \bar{v} /\left\{x^{\prime} v_{2}{ }^{\rho} \rho[\rho(f-1)-1]\right\} \\
=\exp \left\{-\rho\left[2 \sigma_{\mathrm{ec}}-\zeta \Delta f_{\mathrm{u}}+\zeta R T\left(V_{\mathrm{A}} / V_{1}\right)\left(1-\chi_{1}\right)\right.\right. \\
\left.\left.\quad-\zeta R T \ln X_{\mathrm{A}}\right]\right\} / R T
\end{aligned}
$$

where $x^{\prime}=x V_{1}$. Taking the logarithm of eq A-7 and making use of $x^{\prime} / \bar{v}=M, \quad \chi_{1}=B^{\prime} V_{1} / R T_{\mathrm{m}}{ }^{\mathrm{g}}$ and $\Delta f_{\mathrm{u}}=\Delta h_{\mathrm{u}}\left(T_{\mathrm{m}}{ }^{\circ}-T_{\mathrm{m}}{ }^{\mathrm{g}}\right) / T_{\mathrm{m}}{ }^{\circ}$, where $T_{\mathrm{m}}{ }^{\circ}$ is the melting temperature of a perfect crystal and $\Delta h_{\mathrm{u}}$ is the heat of fusion per monomer unit, we obtain

$$
\begin{aligned}
1 / T_{\mathrm{m}}{ }^{\mathrm{g}} & =\zeta /\left(\zeta \Delta h_{\mathrm{u}}+\zeta B^{\prime} V_{\mathrm{A}}-2 \sigma_{\mathrm{ec}}\right) \\
& \times\left(\Delta h_{\mathrm{u}} / T_{\mathrm{m}}{ }^{\circ}+R V_{\mathrm{A}} / V_{1}-R \ln X_{\mathrm{A}}\right) \\
- & R / \rho\left(\zeta \Delta h_{\mathrm{u}}+\zeta B^{\prime} V_{\mathrm{A}}-2 \sigma_{\mathrm{ec}}\right) \\
& \times\left\{\left(\ln \left\langle M_{w}\right\rangle+(\rho-1) \ln v_{2}+\ln \rho[\rho(f-1)-1]\right\}\right.
\end{aligned}
$$

Here we used the weight-average molecular weight.

\section{REFERENCES}

1. A. Takahashi, T. Nakamura, and I. Kagawa, Polym. J., 3, 207 (1972).

2. A. Takahashi, Polym. J., 4, 379 (1973).

3. A. Takahashi and S. Hiramitsu, Polym. J., 6, 103 (1974).

4. T. Kato, M. Yokoyama, and A. Takahashi, Colloid Polym. Sci., 256, 15 (1978).

5. A. Takahashi, T. Kawaharada, and T. Kato, Polym. J., 11, 671 (1979).

6. R. Benson, J. Maxfield, D. E. Axelson, and L. Mandelkern, J. Polym. Sci., Polym. Phys. Ed., 16, 1583 (1978).

7. P. J. Lemstra and G. Challa, J. Polym. Sci., Polym. Phys. Ed., 13, 1809 (1975).

8. M. Girolamo, A. Keller, K. Miyasaka, and N. Overbergh, J. Polym. Sci. Polym. Phys. Ed., 14, 39 (1976).

9. E. D. Atkins, D. H. Isaac, A. Keller, and K. Miyasaka, J. Polym. Sci. Polym. Phys. Ed., 15, 211 (1977).

10. H. Berghmans, F. Govaerts, and N. Overbergh, $J$. Polym. Sci., Polym. Phys. Ed., 17, 1251 (1979).

11. L. Mandelkern, "Crystallization of Polymers," McGraw-Hill, New York, New York, N.Y., 1964, pp 113 and 308.

12. H. Matsuda, K. Araki, and S. Kuroiwa, Polym. Prepr. Jpn., 27, 1540 (1977).

13. S. Nakano and Y. Goto, J. Appl. Polym. Sci., 20, 3313 (1976).

14. P. J. Flory, J. Chem. Phys., 18, 108 (1950).

15. M. S. Muthana and H. Mark, J. Polym. Sci., 4, 527 (1949). 


\section{Sol-Gel Transition of Polyethylene Gels}

16. J. E. Eldridge and J. D. Ferry, J. Phys. Chem., 58, 992 (1954).

17. M. A. Harrison, P. H. Morgan, and G. S. Park, Faraday Discuss. Chem. Soc., on "Gels and Gelling Processes," No. 57, p 38 (1974).
18. M. G. Broadhurst, J. Res. Natl. Bur. Stand., A66, 241 (1962).

19. P. J. Flory, "Principles of Polymer Chemistry," Cornell University Press, Ithaca, N.Y., 1953, Chapter IX. 